\title{
Optimisation of crest blasting and excavation techniques for controlling spillover at Bingham Canyon Mine
}

\author{
J Morkeh Rio Tinto Kennecott Copper, USA \\ J Cefalo Rio Tinto Kennecott Copper, USA \\ K Robertson Rio Tinto Kennecott Copper, USA
}

\begin{abstract}
The height of the south wall at Bingham Canyon mine, running east to west, ranges between $100 \mathrm{~m}$ to $400 \mathrm{~m}$ tall. This wall, which is currently being mined down as part of the Slice 1 pushback, sits above the only haul road used to access the pit bottom - which hosts most of the mine's ore. Consequently, rockfall from the operating mining level onto the haul road is a critical risk to the operation.

Earlier reviews including rockfall simulations and rockfall barrier analysis work recommended implementing crest blasting procedures and mining with smaller hydraulic shovel to control spillover so that the rockfall control barrier on the haul road can continue to be effective. Initially, a conservative crest blasting technique was used to control spillover, however this approach posed challenges in the mining sequence and impacted overall productivity of the pushback. The blast designs and crest mining methodology were gradually adjusted following reviews of blast performance and monitoring data. This paper details the blasting-mining-spillover evaluation process and the subsequent mining operational changes that were made to improve production in the current pushback while controlling spillover.
\end{abstract}

Keywords: spillover control, rockfall control, crest blasting, crest mining

\section{Introduction}

As orebodies become increasingly deeper from the ground surface (Wood et al. 2012), mining processes have to be refined to make the extraction of the valuable materials economic. Most mining companies are deploying innovative processes to make new mining areas, including pushbacks work. Some of these processes pose slope hazards that have to be managed by implementation of site-specific terms depending on the risk. Rio Tinto Kennecott Copper's Bingham Canyon Mine (RTKC) has found an innovative process to manage rockfall and spillover risks resulting from vertically coincidental mining (VCM). Figure 1 shows an example of VCM on the east wall of RTKC, from the newer pushback (E7) to the older pushback (E6).

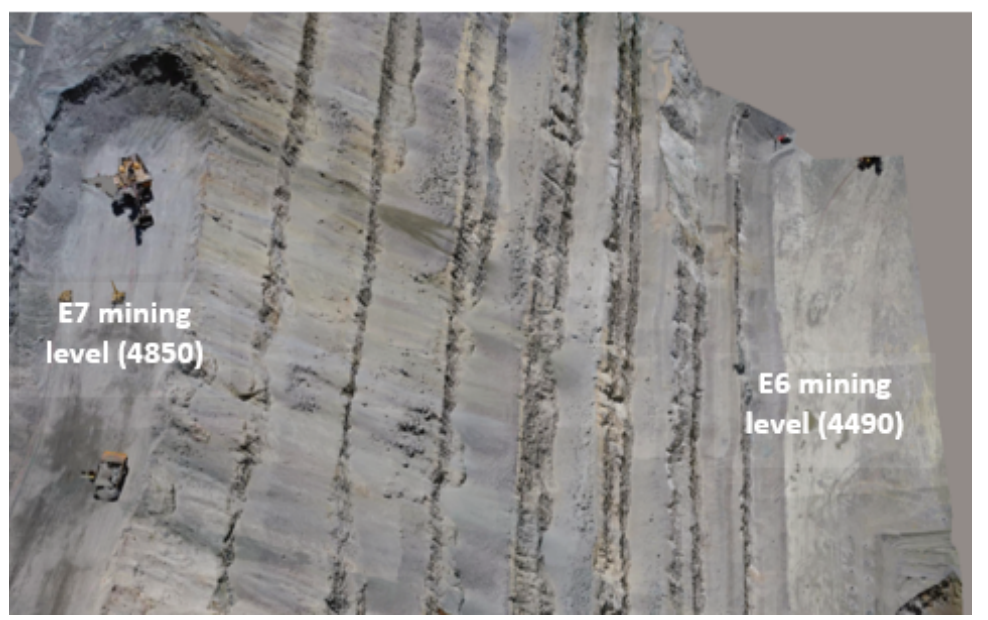

Figure 1 Example of vertical coincident mining (VCM) on the east wall of the Bingham Canyon Mine 
RTKC has been proactive in dealing with spillover and rockfall issues that results from VCM. A trigger action response plan (TARP) was developed to manage these slope hazards. Figure 2 shows an illustration of how the VCM between the E7 and E6 mining levels were managed.

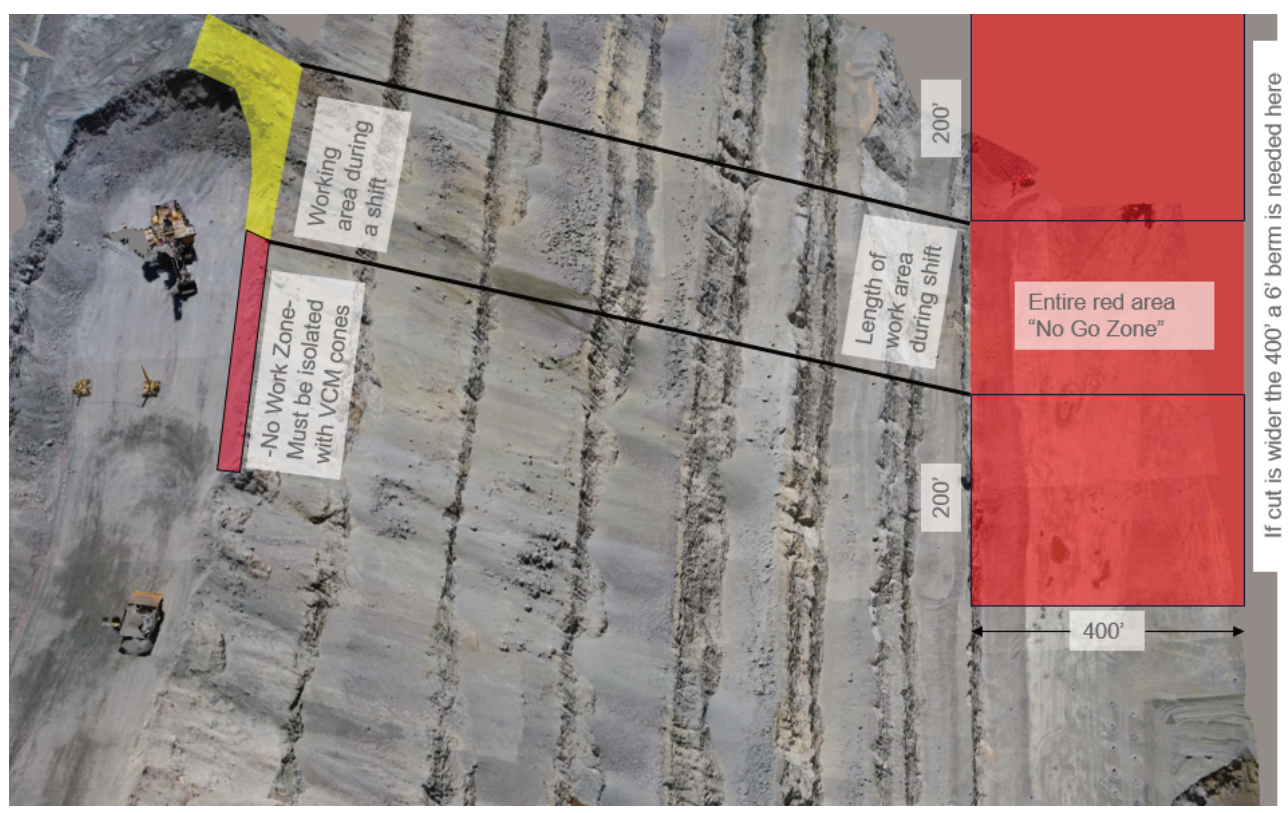

Figure 2 Managing rockfall risks associated with vertical coincident mining (VCM) on the east wall of the Bingham Canyon Mine from Rio Tinto Kennecott Copper (2016)

The south wall of the Bingham Canyon Mine, which is currently being mined down as part of the Slice 1 pushback, sits above the only haul road access to the bottom of the pit, where most of the pit's ore is located. Consequently, rockfall from the operating mining level onto the haul road is a critical risk to the operation.

Extensive work was completed by a diverse group of engineers from different companies to identify controls needed on the south wall of RTKC mine. This project team was comprised of personnel from Rio Tinto's Bingham Canyon Mine, University of Arizona's Geotechnical Centre of Excellence and Golder Associates Inc. The team conducted a site-specific calibration and utilised a predictive rockfall model including field testing of the design, and implementation and monitoring of the controls in place, to design and implement an effective rockfall control. Details of this work has been published by Williams et al. (2019).

The rockfall controls defined in Williams et al. (2019) are L-panel concrete structures for rockfall protection where high energies or bounce heights were expected, and sea container stacks linked together laterally for areas of predicted lower energies and bounce heights. With these controls in place on the major haul road to control rockfall hazards, effort was made to reduce the amount of material that spills over from the Slice 1 south wall slope.

Most published mine blast optimisation work has focused on issues such as: overbreak, slope stability, air blast, wrong fragmentation, vibration issues and fly rocks. Some of the publications that tackled the abovementioned issues include Bowa (2015), Afeni (2009) and Ninepence et al. (2016). None of the mine blast optimisation work reviewed for this paper focused on an optimisation approach to control spillover in an active large-scale open pit mine.

The main objective of this paper is to share how the blast designs and crest mining methodology were gradually adjusted following reviews of blast performance and monitoring data. Achieved results including details on drill flexibility, creating inventory and ultimately improved tonnes per operating hour of the current Slice 1 cut will be shared as well.

Figure 3 shows the slope below the Slice 1 cut with height and inter-ramp angle details. 


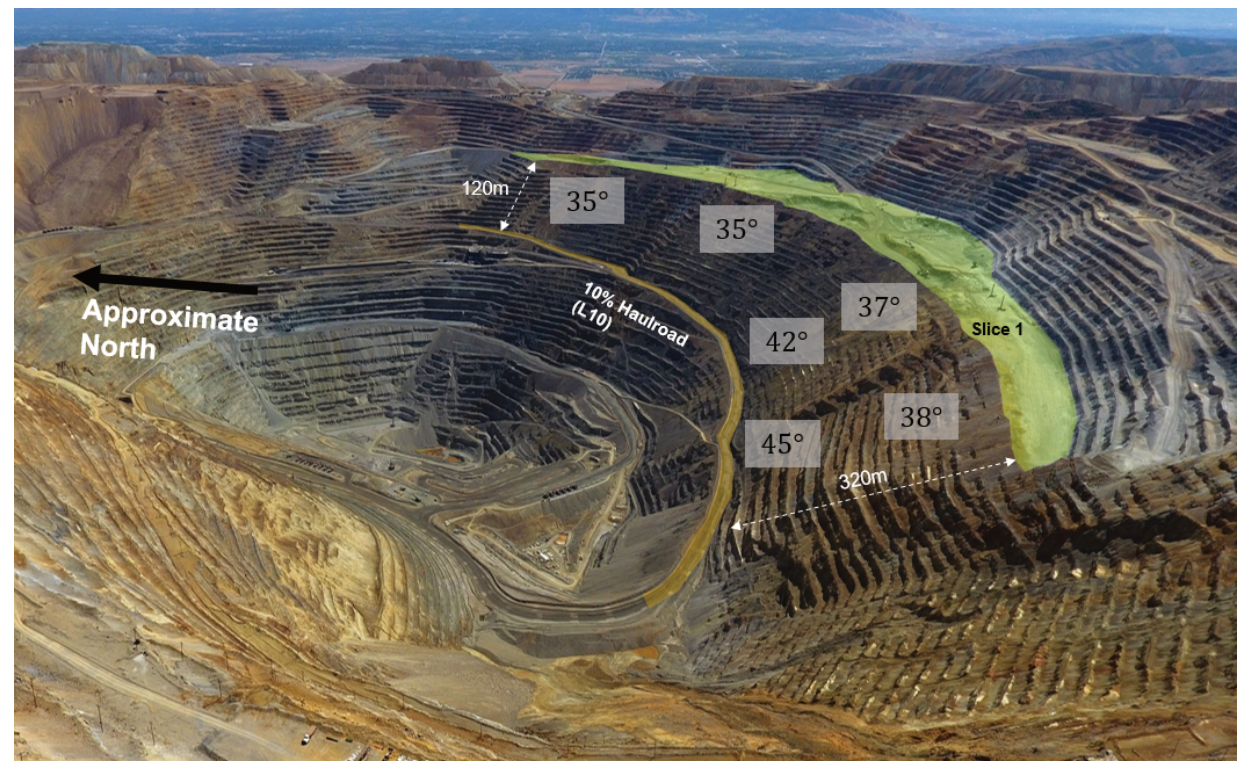

Figure 3 South wall showing slope height and inter-ramp angles

\subsection{Engineering geology of Slice 1 pushback}

The Slice 1 cut is composed of predominantly: quartzite with siltstone, sandstone, and limestone interbeds. Monzonite is the dominant intrusion in Slice 1, with some Quartz Monzonite Porphyry (QMP), Porphyritic Quartz Monzonite (PQM), Latite Porphyry (LP) and others. These intrusions caused a minor metamorphic hardening in the sediments as well as hydrothermal alterations of varying types and degrees. There are multiple major fault zones in the area, from reactivation of the Giant Chief and related faults to fissure style, almost exclusively on the south wall. Using the field estimate for the uniaxial compressive strength (UCS) found in Read \& Stacey (2009), the limestone, altered to wollastonite calcite marble is the strongest with an estimate of R5-R6. Limestone in its purest state is about R3 on field estimation rock strength scale. The monzonite is the weakest rock with average field estimation rock strength rating of R2-R3. Mostly, the monzonite and quartzite rocks respond well to blasting, producing desired fragmentation for digging. However, the limestone, because of its hardness and altered nature, does not blast well and can leave hard digging toes. The most challenging part of blasting in the Slice 1 cut is achieving the desired fragmentation of the limestone beds without compromising the integrity of the highwall. Figure 4 shows a schematic geology overview image of the Slice 1 cut.

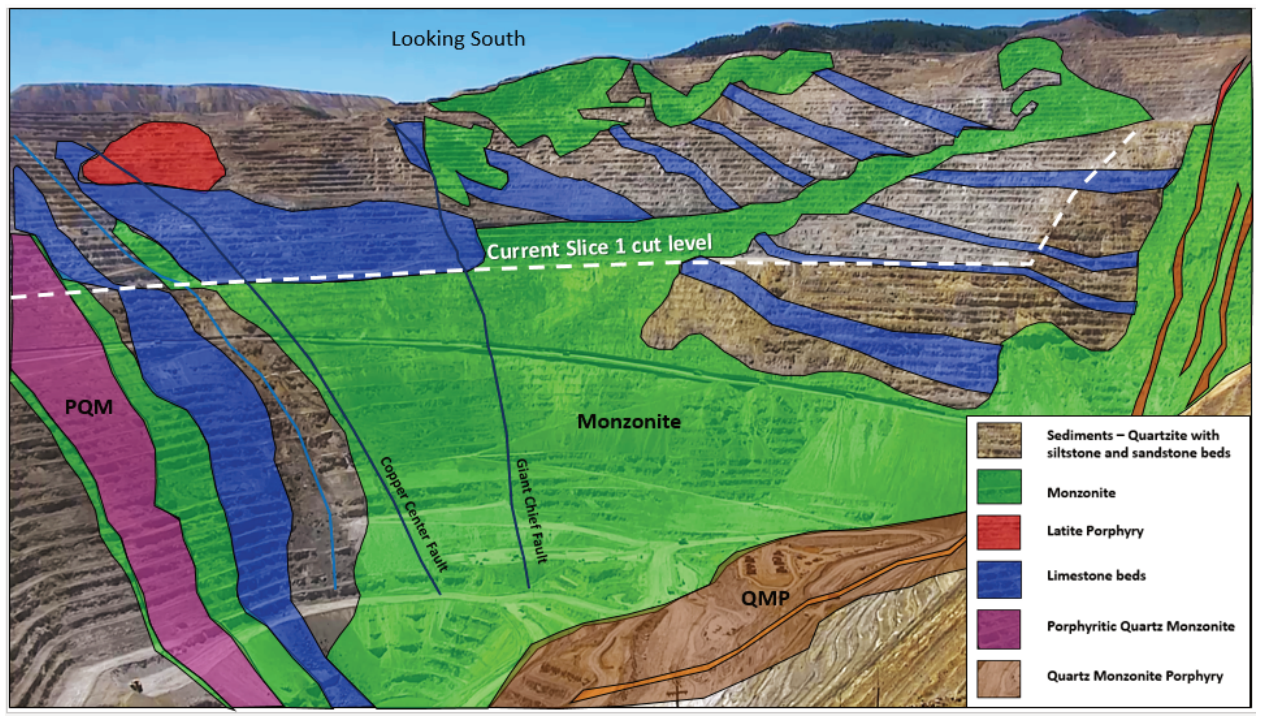

Figure 4 South wall showing geologic overview of the Slice 1 cut, from Gibbs et al. (2019) 


\section{$2 \quad$ Methodology}

Prior to the use of controlled crest blasting and mining technique, conventional blasting and mining approaches were used on the crest of the Slice 1 pushback. The blast utilised the crest as the free face and casted material from the crest onto the south wall slope. Timing for blasts allowed for large movement towards the free face. Figure 5 shows a typical crest blasting approach before adopting the current crest blasting techniques.

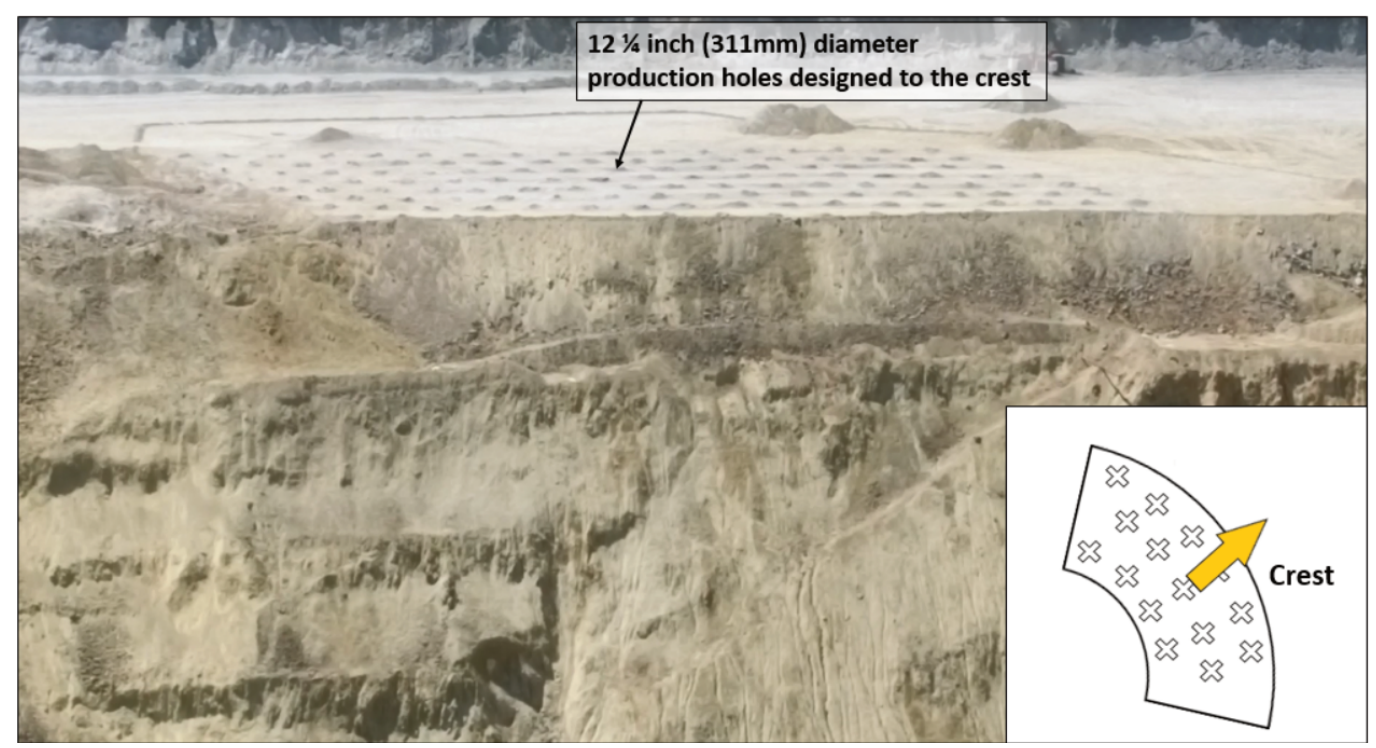

Figure 5 Illustration of conventional blasting method used prior to installation of rockfall controls on $10 \%$ haul road

The following processes were used to minimise the amount of material that casted over from Slice 1 pushback onto the south wall slopes.

\subsection{Crest trim blasting using $77 / 8$ inch $(200 \mathrm{~mm})$ diameter holes}

The first and most conservative approach that was adopted included blasting a trim-like crest pattern onto a free face area created from mining a relatively bigger production pattern. The drilled holes were $7 \% / 8$ inch $(200 \mathrm{~mm})$ diameter holes with low powder factor and the material was timed to pull into the shovel cut. Figure 6 shows an example of this blast type.

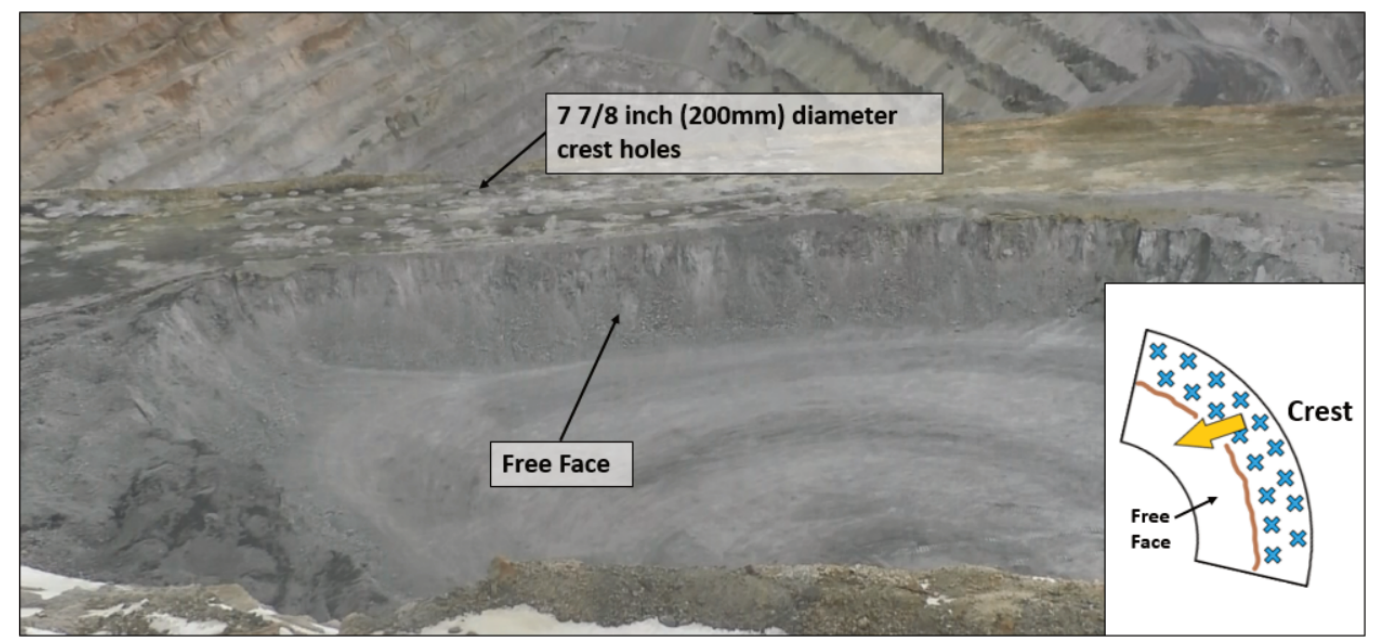

Figure 6 Illustration of free faced crest trim blasting using $7 \% / 8$ inch diameter holes 


\subsection{Combination (combined production and trim) blasting - free faced}

The second approach that was adopted was blasting a combination of trim-like crest pattern as described in Section 2.1 and a production pattern onto a free face area created by mining of a similarly blasted pattern. The diameter of the crest and production holes used here were $7 \% / 8$ inch $(200 \mathrm{~mm})$ and $12 \%$ inch $(311 \mathrm{~mm})$ respectively. The pattern is shot together as one blast. Figure 7 shows an example of this blast type. The first blasted free faced combined production and trim pattern is usually at an area with relatively good catch capacity. Sections of the layback were narrow and did not allow for a crest pattern to be free faced so the production in the centre of the bench was blasted with the crest. In the beginning all the patterns were free faced to allow material to move into the bench and not push on the crest. Currently, with the improved methodology, the pattern can be shot onto a shot muck. In this case the material is blasted and pulled upwards from the middle of the pattern.

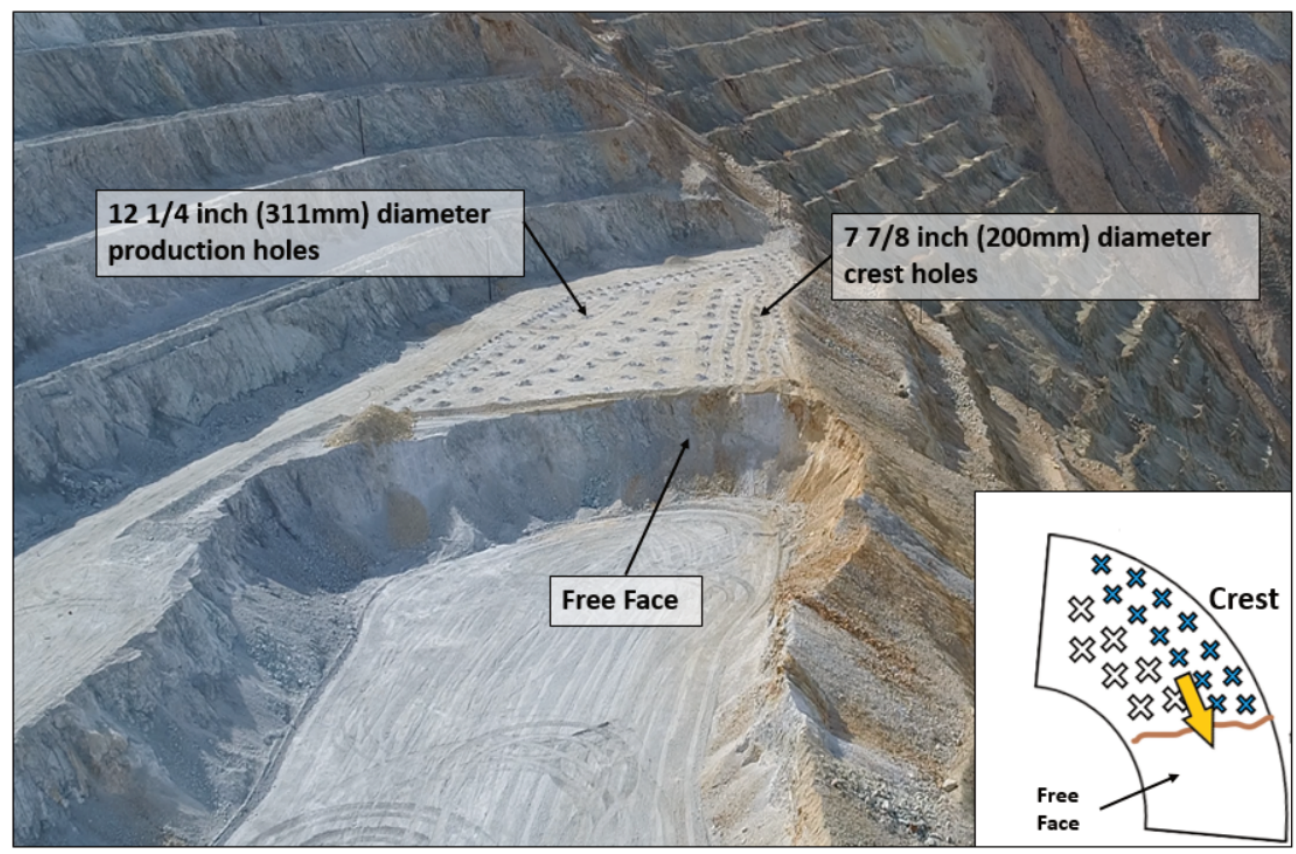

Figure $7 \quad$ Illustration of crest trim and production (combination) blasting with a free face

\subsection{Combination (combined production and trim) blasting - narrow production}

In narrow areas (areas with less than $100 \mathrm{~m}$ width), the combination blast procedure described in Section 2.2 is utilised without an already established free face. The material is blasted towards already blasted material (shot muck). The diameter of the crest and production holes used here are also respectively $7 \% / 8$ inch (200 $\mathrm{mm}$ ) and $12 \frac{1}{4}$ inch $(311 \mathrm{~mm}$ ). Example of this combination blast in narrow production face is shown in Figure 8. When sequence allow, the narrow production combination blast are free faced. The main objective during this kind of blast as illustrated by Figure 9 is to control spillover with the crest trim pattern, achieve good fragmentation with the production pattern in the middle and finally attain a good wall control with the highwall trim. 


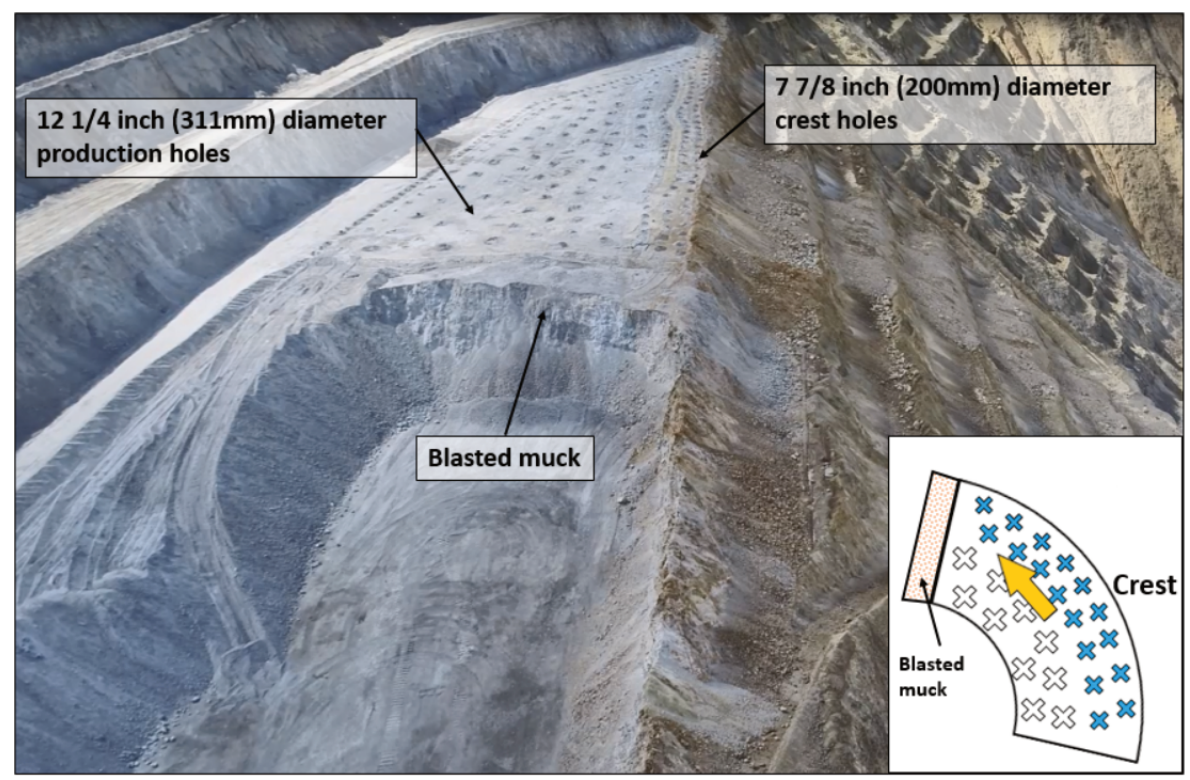

Figure 8 Illustration of crest trim and production combination blasting in a narrow production

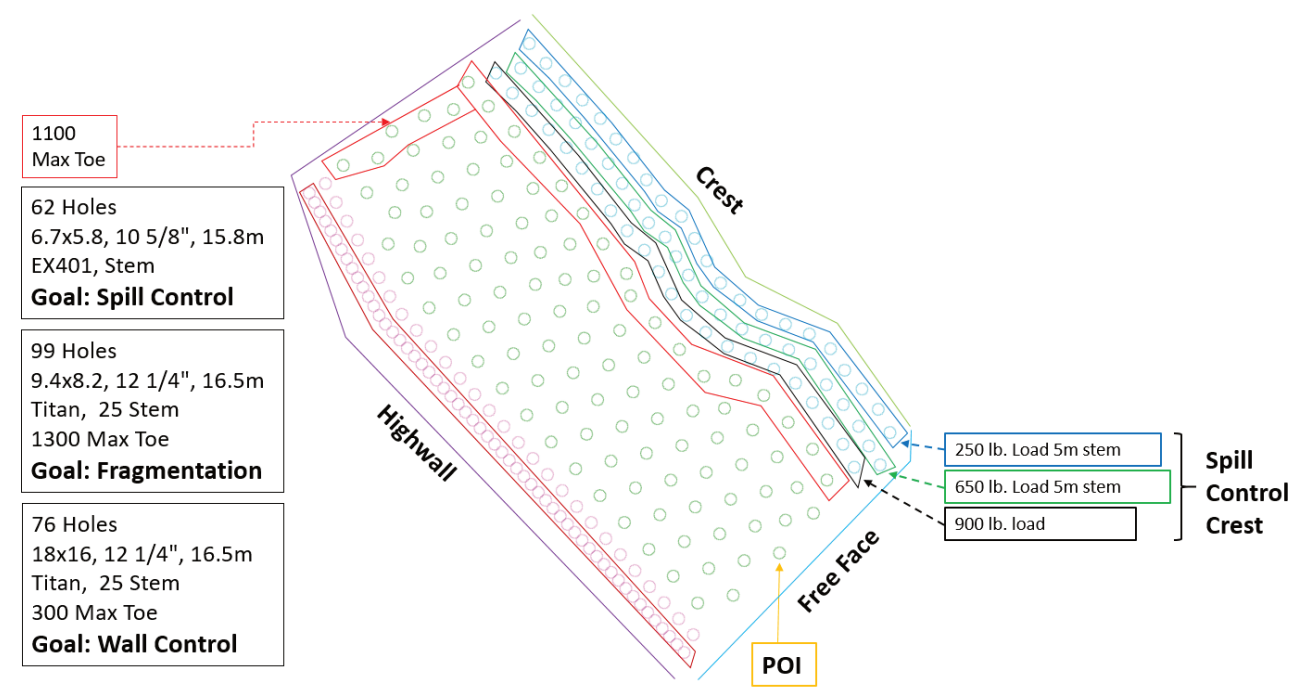

Figure 9 Illustration of combination blasting in a narrow production with pattern information

\subsection{Slice 1 pushback sequence - optimised free faced combination blasting}

Figure 10 shows the sequence utilised for both blasting and mining of a bench in the Slice 1 pushback. The beginning benches, when starting with crest control measures, required that the benches were mined out in the middle of the cut first so that the crest patterns could blast into the bench.

Figure 10a, the ramp was blasted with patterns shapes 1 and 2 . The cut would open up in pattern shapes 3 and 4 that would be used to free face the crest blast.

Figure 10b, pattern 6 would be the free faced crest blast that would blast into the shovel cut. Other production patterns would be blasted to the side of the crest blast that would serve as backup material while the crest was being drilled and blasted. Consequently, the crest pattern would be mined out free facing the next crest blast.

Figures 10(c) and 10(d), after the crest blast the shovel would mine out the material to free face the next crest patterns to blast to the free face on the crest. The production patterns would continue to be blasted down both sides of the bench free facing the crest. 


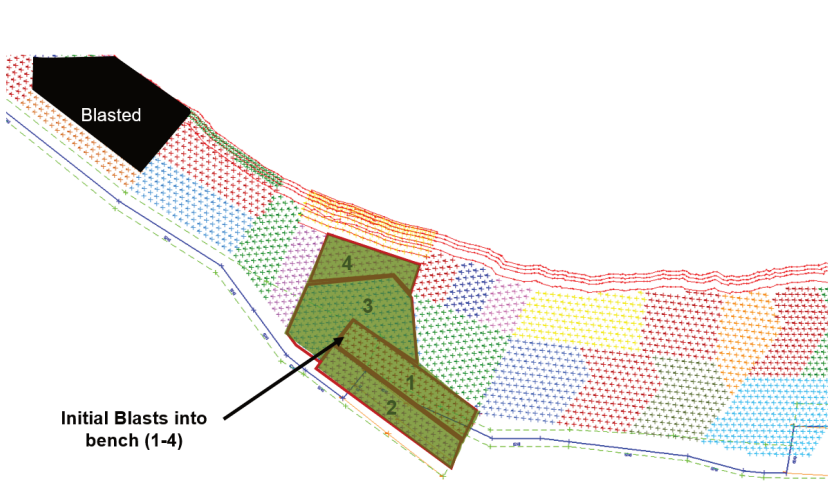

(a)

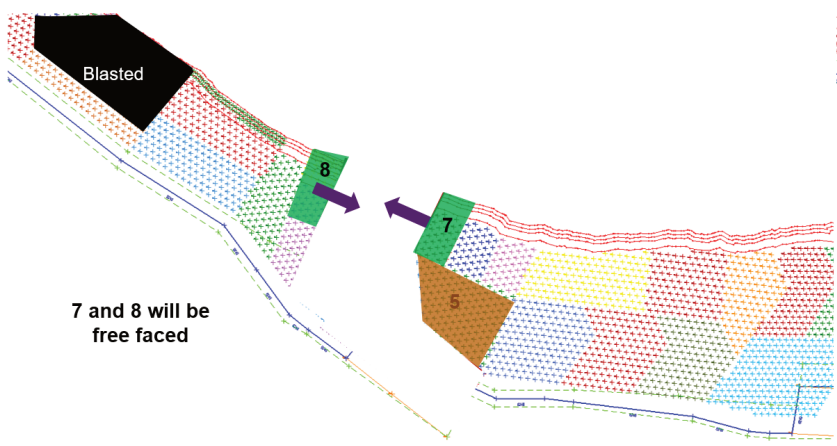

(c)

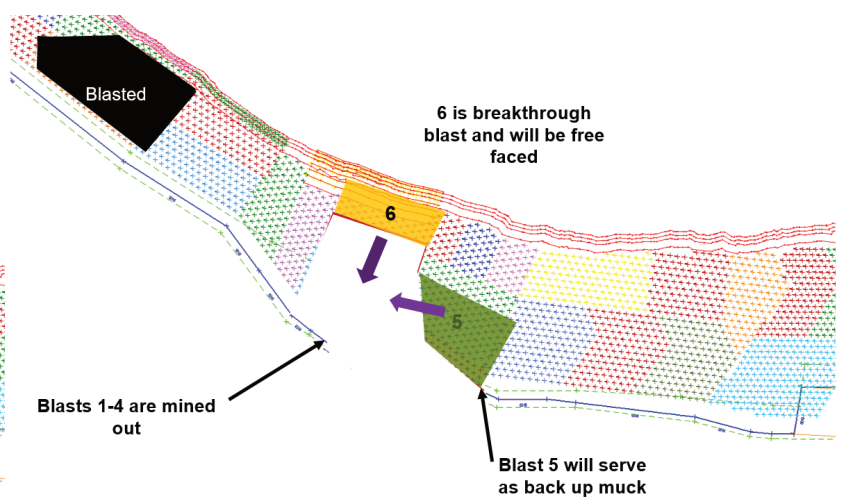

(b)

Figure 10 Illustration of Slice 1 pushback sequence using optimised free faced combination blasting

\subsection{Crest blast performance}

The entire south slope was analysed in sectors. Each sector is based on such distinguishable factors as slope height, inter-ramp angle, and geology and catch capacity. Based on the amount of catch capacity on a slope sector, a numeric value was assigned to that sector indicating the maximum amount of material that can be spilled per bench, usually expressed in tonnes per linear foot. Figure 11 shows crest blast performance on 6190 bench. Red colour indicates that the maximum spillover for the bench was exceeded with green and black colours indicating values below maximum value and no data for the area respectively. This process is reviewed on a weekly basis.

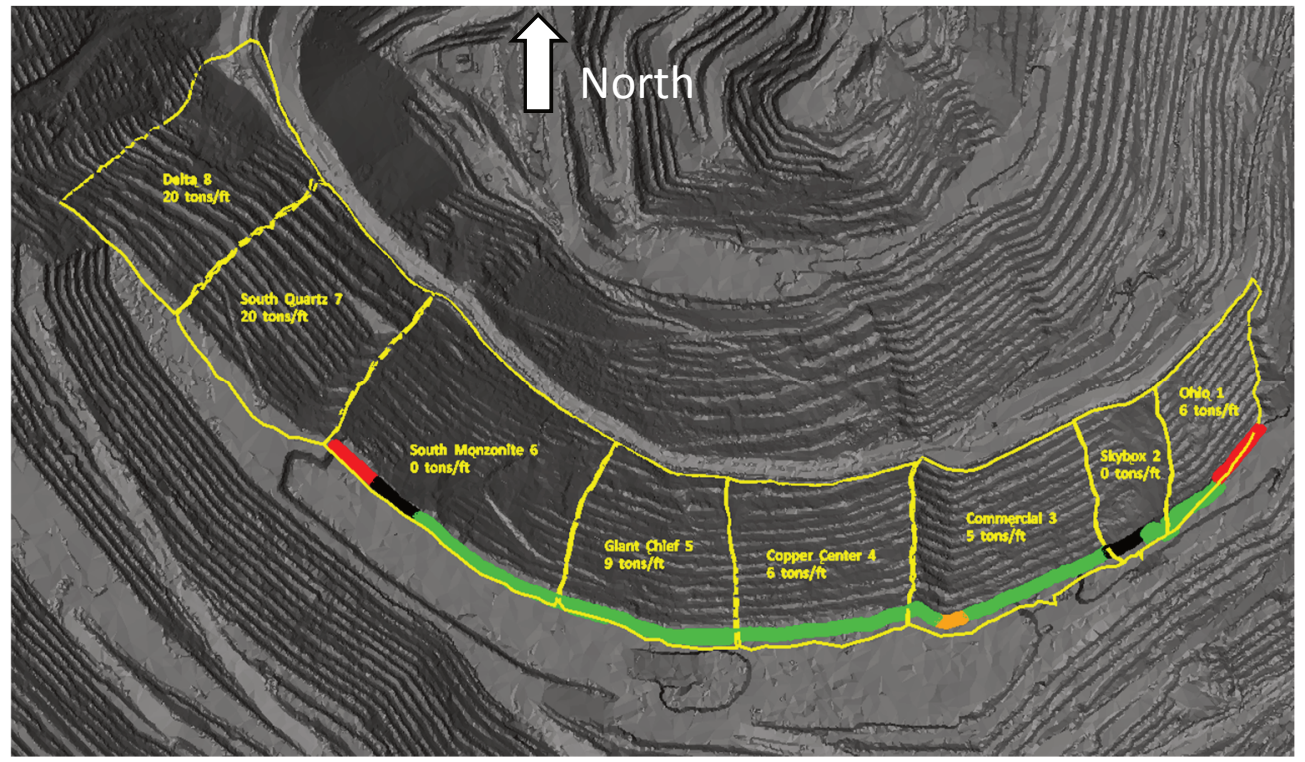

Figure 11 Slope sectors showing maximum spillover amount and performance 


\subsection{Crest mining approach}

As described in Williams et al. (2019), large electric rope shovels, which digs by pushing the dipper away from the machine, were not allowed to dig the crest due to the amount of spillover and rockfall caused by this method. Consequently, a stand-off for electric shovels was established and applied using the CAT Mine-star Terrain system. This left a berm material of approximately $15 \mathrm{~m}$ tall and $15 \mathrm{~m}$ wide on the outside crest. A smaller hydraulic shovel (Hitachi 5500) configured as an excavator was then used to pull the remaining material in from the crest, keeping a $2 \mathrm{~m}$ tall berm on the outside. The process of using an excavator to pull material in from the crest reduced the amount spillover caused by crest mining significantly.

\section{Data}

Crest blast performance review meetings are done on a weekly basis with the drill and blast engineer, operations drill and blast personnel, mine planning engineer or a scheduler and a geotechnical engineer. During this weekly meeting, highwall monitoring data, drone videos of blast, post crest blast report, visual inspections etc. are presented and discussed. Lessons learned from previous crest blasts are discussed and corrective actions noted to be included in the upcoming crest blasts. Figure 12 shows a post blast report that is sent out after every crest blast. The information contained in the report is recorded, tracked and reviewed by the aforementioned team for optimisation purposes.

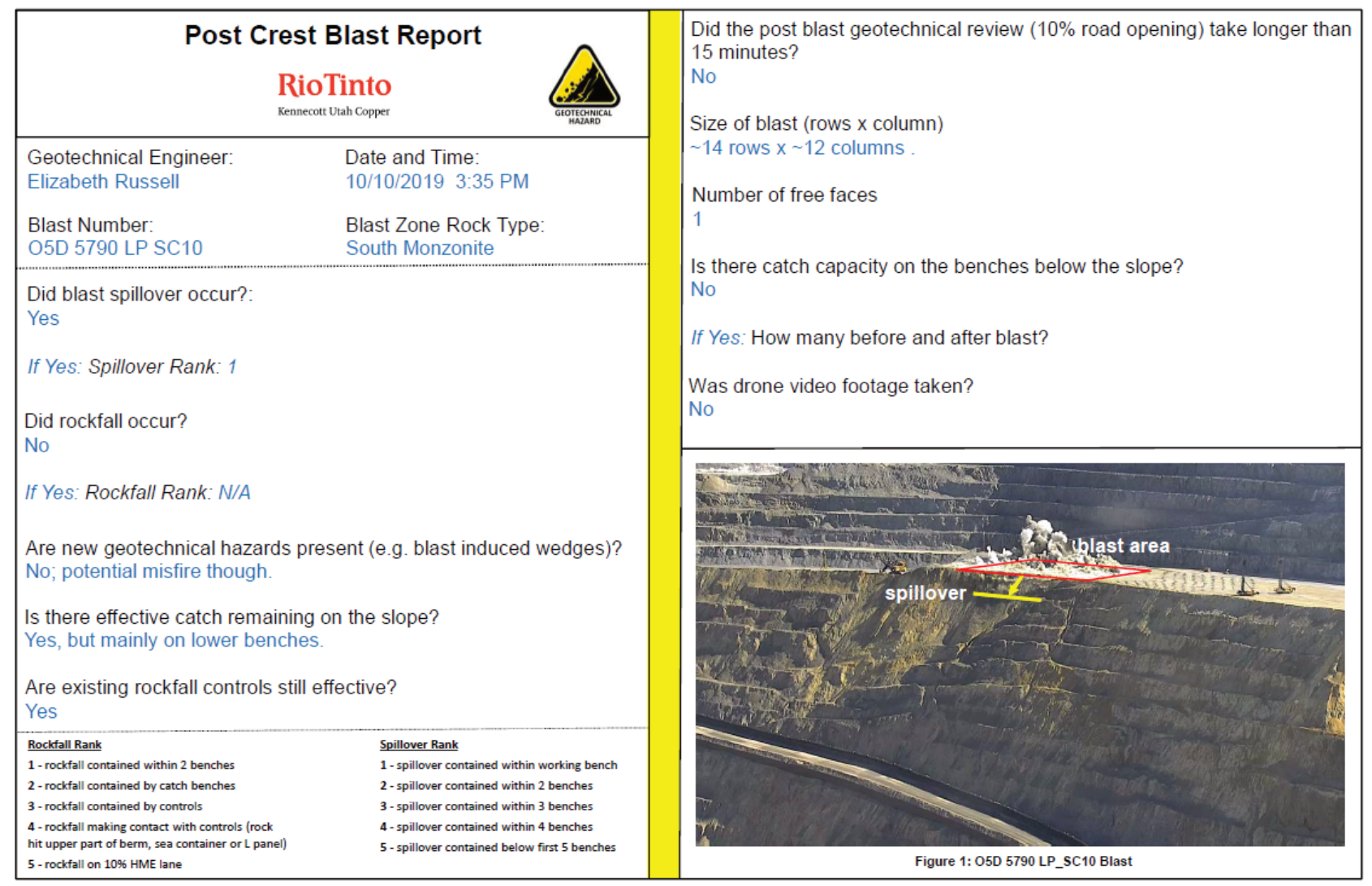

Figure 12 Example of a post crest blast report, from Rio Tinto Kennecott Copper (2017)

\section{$4 \quad$ Results}

The following describes the operational adjustments that were made to realise optimum performance of the Slice 1 pushback. A lot of these adjustments became possible after trials in areas of the slope with relatively higher catch capacity, mostly either the east end or west end of the cut. The changes were mostly incremental until the most optimal result was realised. 


\subsection{Optimising crest trim blastholes}

The diameter of crest trim blastholes started as $7 \% / 8$ inch $(200 \mathrm{~mm})$ and subsequently progressed to $105 / 8$ inch $(270 \mathrm{~mm})$ in most areas. Currently, only two sections out of the eight total sections on the south wall showed in Figure 11 still uses $7 \% / 8$ inch $(200 \mathrm{~mm})$ diameter blastholes, the rest of the sections uses the 105/8 inches $(270 \mathrm{~mm})$ holes. The reason for the continual use of the $7 \% / 8$ inch $(200 \mathrm{~mm})$ blast diameter holes at those two sections is because of limited catch capacity on those sections of the slope. Drilling less $7 \% / \mathrm{inch}(200 \mathrm{~mm})$ blastholes means: less drilling in general, an increase in availability of the trim drills, reduces production costs and improves drilled inventory.

\subsection{Size of crest trim pattern}

Initially, a minimum of three crest trim rows with a maximum of eight holes per row was designed, loaded and blasted to reduce spill over. Currently, two rows of crest trim with 16 holes per row is designed, drilled, loaded and blasted. This increases the availabilities of the trim drills and also help to reduce the amount of hard digging spots on the crest due to low powder factor used in the crest trim holes.

\subsection{Crest trim and production combination blasting}

Originally, every crest blast was required to be three rows with eight $77 / 8$ inch ( $200 \mathrm{~mm}$ ) holes per row and blasted free faced, illustrated in Figure 6 . With regular blast performance reviews and successful incremental trials, it was optimised to combination blasting of several rows of production $\left(12 \frac{1}{4}\right.$ inch $\left.(311 \mathrm{~mm})\right)$ holes and two trim (7\%/8 inch $(200 \mathrm{~mm})$ ) rows with 16 holes per row, blasted free faced (Figure 7) or blasted and pulled unto a shot muck if it is a narrow bench (Figure 8). Currently, there is no area in the Slice 1 pushback that requires stand-alone crest trim blasting (Figure 13). This is reviewed after completion of every bench to ensure the controls for spillover and rockfall are adequate.

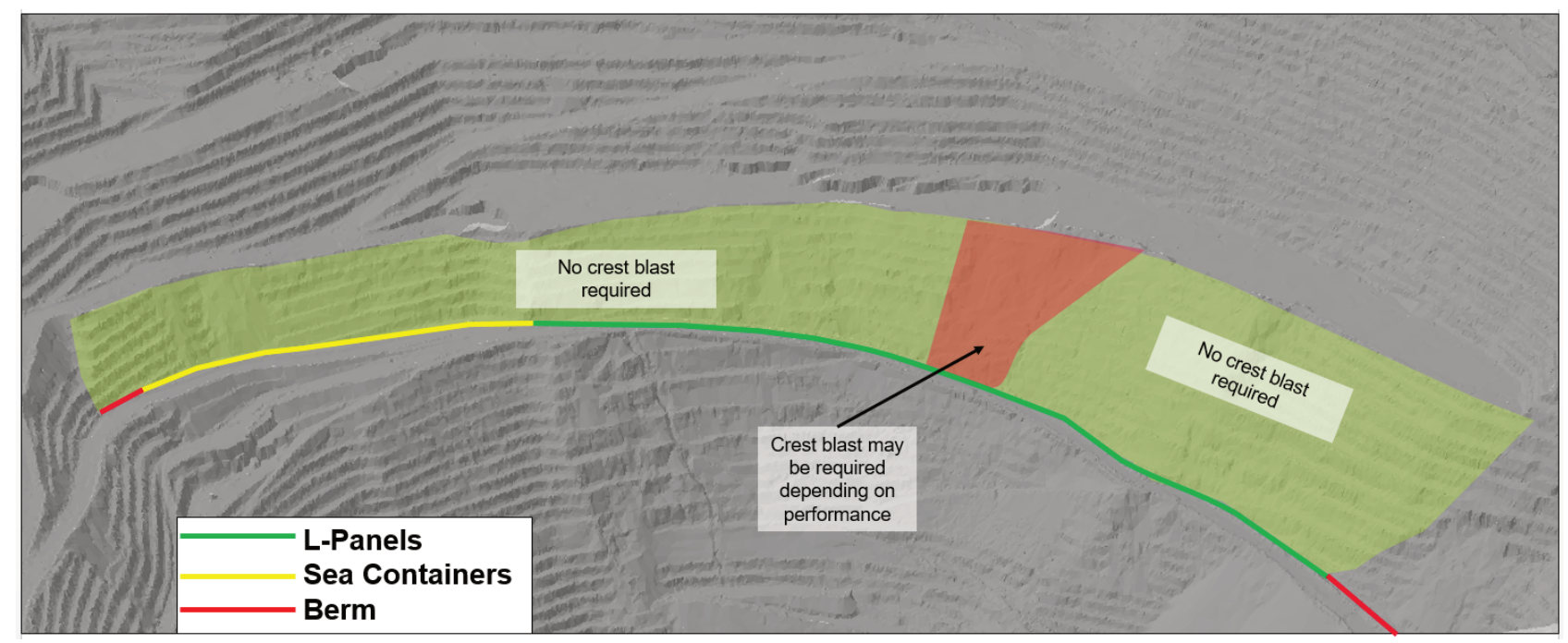

Figure 13 Currently no stand-alone crest trim blast required on the Slice 1 pushback

\subsection{Crest mining stand-off distance}

The initial stand-off distance for the rope shovels discussed under Section 2.6 was approximately $15 \mathrm{~m}$, with subsequent re-training of shovel operators, performance review and monitoring, the stand-off distance for the rope shovels was reduced to approximately $8 \mathrm{~m}$. This reduces the amount of digging the hydraulic shovel has to perform, increasing the efficiency of the rope electric shovels. Because certain areas on the south slope has limited or no catch capacity, there are still areas that have to honour the $15 \mathrm{~m}$ stand-off for the rope shovels. Figure 14 shows areas where rope shovels can dig at the crest (green) and where rope shovels need to stand-off approximately $8 \mathrm{~m}$ from the crest. This is reviewed after completion of every bench. 
Figure 15 shows in-field execution of crest mining by a hydraulic shovel where crest stand-off is required for a rope shovel.

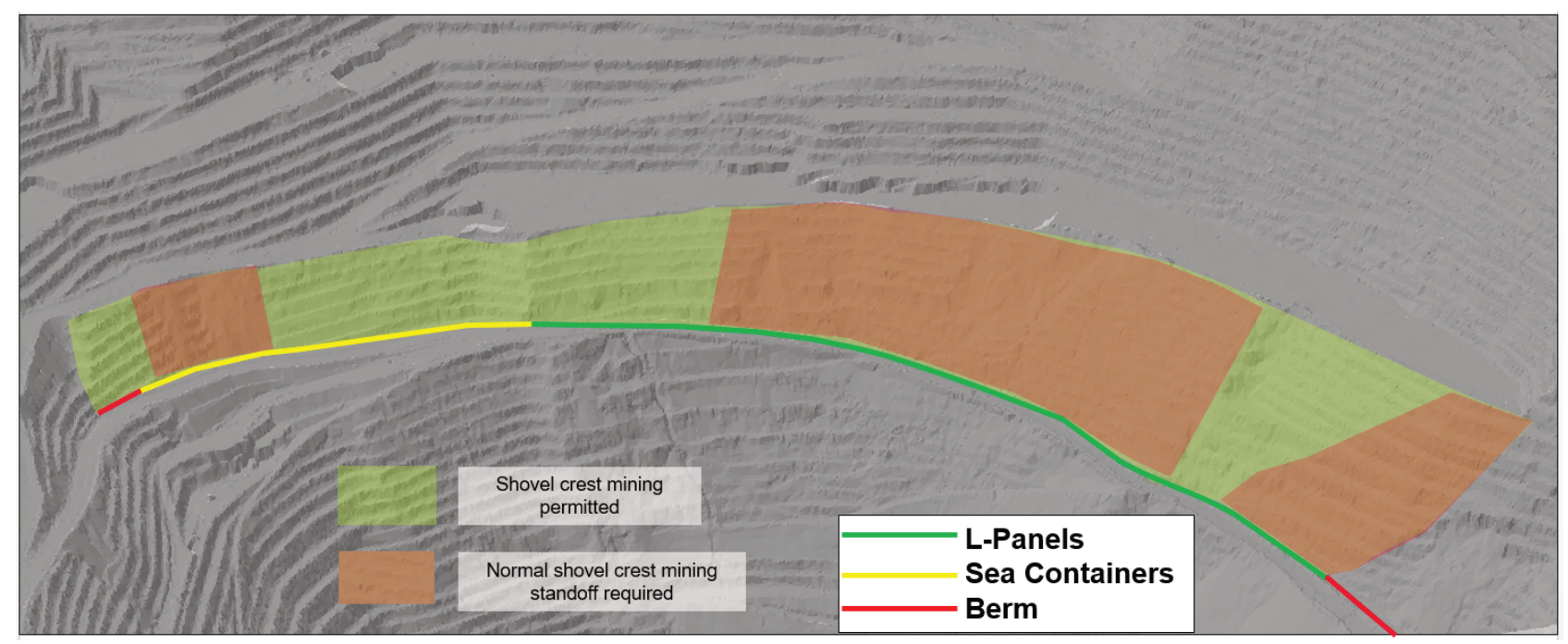

Figure 14 Areas where $15 \mathrm{~m}$ and $8 \mathrm{~m}$ stand-offs are required for rope electric shovels

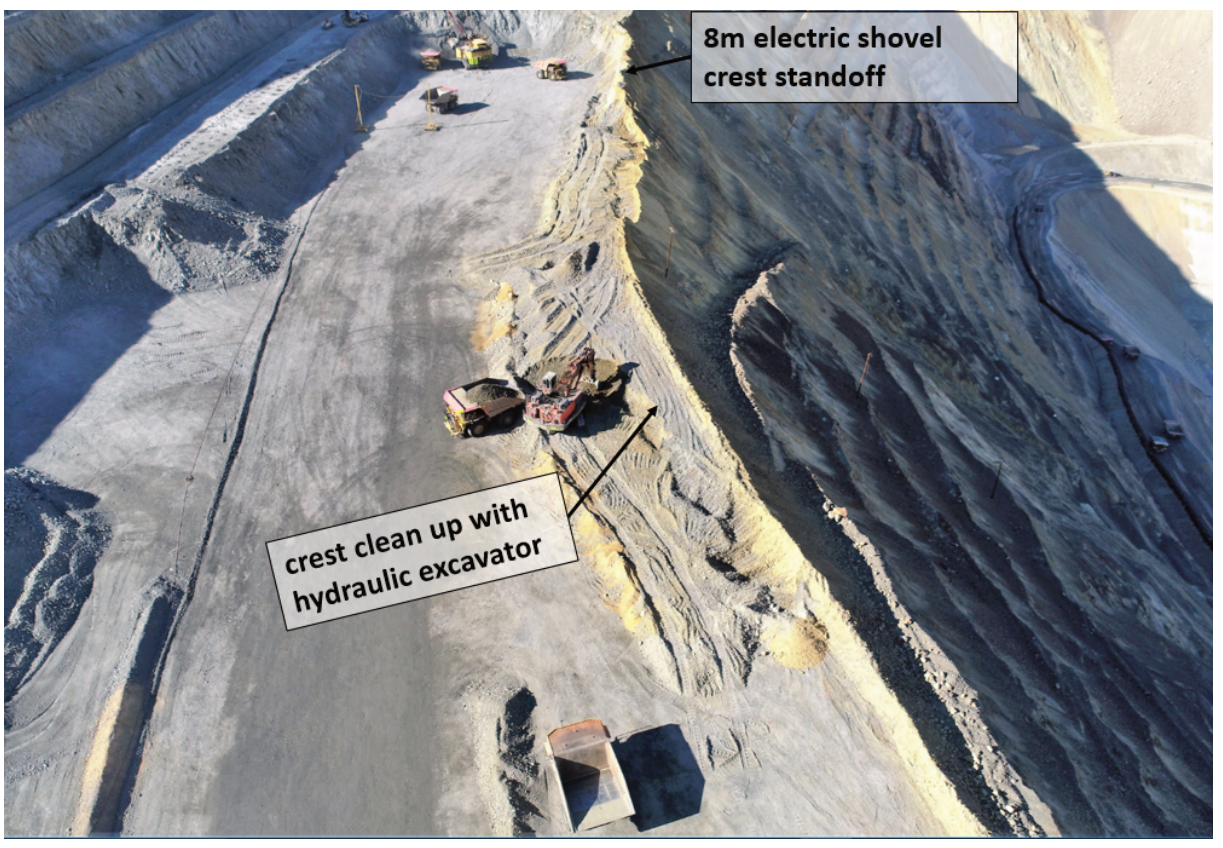

Figure 15 Crest mining using hydraulic shovel where crest stand-off is required for rope shovel

\section{Conclusion}

After the engineered rockfall controls were placed on the $10 \%$ haul road, a conservative approach to crest blasting and mining was implemented to reduce the amount of material being casted over onto the south wall slopes. The blasting and mining methodologies implemented were gradually adjusted following reviews of performance and monitoring data.

Some of the challenges faced when the initial methodologies were implemented included: Increased trim drill requirements because of three rows of small diameter holes on crest, difficulty to build shot muck inventory due to the frequent small blasts, frequent shovel moves between faces because of shovel digging out free face but running out of backup muck and idling until another blast and finally some areas on the cut being too narrow for a separate production and trim blasts. 
The following were implemented to optimise crest blast and mining practices for efficient mining of the Slice 1 cut:

Drill flexibility $-10 \%$ inch $(270 \mathrm{~mm})$ crest blasting:

- This has allowed production rigs to drill all of the pattern and reduce the issues of trim drill availability.

- Increased production drill efficiency and reduction of drill moves (able to drill more holes in a single move).

Creating inventory - refine free facing blast requirements:

- Identified crest blasts in areas with more catchment capacity - trialled using adjacent shot muck as relief (same blast movement direction - parallel to crest).

- Allowed for inventory buildup in front of shovel, remove the need for 'backup' muck faces, reducing shovel moves and drill and blast delays.

Large blast - more inventory - combining crest with full production pattern:

- Identified crest blasts that may be combined with larger productions patterns, this will allow the drill fleet to get ahead in blasted inventory and reduce the amount of moves on drills.

- Sections of Slice 1 are too narrow to free face both a crest and trim.

- As combination blasts are successful in the narrow sections, the practice is then extended to wider sections of Slice 1 cut.

- The ability to combine crest and large production patterns allows for a two-shovel cut on the west end of Slice 1, where there is a risk of splitting the cut due to mining duration on the reverse.

To date, approximately $12 \%$ increase in tonnes per operating hour has been achieved through optimising the crest blasting and mining techniques. This increase in tonnes per operating hour is essential to the operation of the Slice 1 cut. Additional improvements, including the number of crest rows and adjustment to crest mining protocol, will be evaluated and ultimately optimised. Review of the rockfall controls on the $10 \%$ road will also be carried out to evaluate when the controls need to be removed or changed.

\section{Acknowledgement}

We want to express our sincere gratitude to Rio Tinto Kennecott Copper for allowing this information to be published and shared with the entire mining industry.

\section{References}

Afeni, TB 2009, 'Optimization of drilling and blasting operations in an open pit mine-the SOMAIR experience', Mining Science and Technology (China), vol. 19, iss. 6, November 2009, pp. 736-739.

Bowa, VM 2015, 'Optimization of blasting design parameters on open pit bench, a case study of Nchanga Open Pits', International Journal of Scientific \& Technology Research, vol. 4, iss. 9, September 2015.

Gibbs, J, Vetz, N \& Hoover, E 2019, September 2019 Geology Mapping, Rio Tinto Kennecott Copper, South Jordan, internal communication.

Ninepence, JB, Appianing, EJA, Kansake, BA \& Amoako, R 2016, 'Optimisation of drill and blast parameters using empirical fragmentation modelling', Proceedings of the Fourth UMaT Biennial International Mining and Mineral Conference, pp. 25-29.

Read, J \& Stacey, P 2009, Guidelines for Open Pit Slope Design, CSIRO Publishing, Collingwood, p. 18.

Rio Tinto Kennecott Copper 2017, Post Blast Report, internal document, Rio Tinto Kennecott Copper, South Jordan.

Rio Tinto Kennecott Copper 2016, Vertically Coincidental Mining (VCM) Trigger Action Response Plan (TARP) Documentation, internal document, Rio Tinto Kennecott Copper, South Jordan.

Williams, C, Morkeh, J, Dorfschmidt, K, Poon, C, Matlashewski, P \& Carvalho, J 2019, 'Innovative rockfall solutions based on calibration and field testing', Mining, Metallurgy \& Exploration, vol. 37, pp. 101-116.

Wood, D \& Brya, WH 2012, Crucial Challenges to Discovery and Mining - Tomorrow's Deeper Ore Bodies, Mining \& Geology Research Centre, The University of Queensland, Brisbane, viewed 14 October 2019, https://www.segweb.org/pdf/news/danwood/Crucial-Challenges-to-Discovery-and-Mining-Tomorrows-Deeper-Ore-Bodies-Text-Only.pdf 
Optimisation of crest blasting and excavation techniques for controlling spillover at Bingham Canyon Mine

$\mathrm{J}$ Morkeh et al. 